This item was submitted to Loughborough's Research Repository by the author.

Items in Figshare are protected by copyright, with all rights reserved, unless otherwise indicated.

\title{
The six relative advantages in multichannel retail for three-dimensional virtual worlds and two-dimensional websites
}

PLEASE CITE THE PUBLISHED VERSION

http://doi.org/10.1145/3292522.3326038

\section{PUBLISHER}

Association for Computing Machinery (ACM)

VERSION

AM (Accepted Manuscript)

\section{PUBLISHER STATEMENT}

(c) ACM 2019. This is the author's version of the work. It is posted here for your personal use. Not for redistribution. The definitive Version of Record was published in WebSci '19 Proceedings of the 11th ACM Conference on Web Science, http://doi.org/10.1145/3292522.3326038

\section{LICENCE}

All Rights Reserved

\section{REPOSITORY RECORD}

Zarifis, Alex. 2019. "The Six Relative Advantages in Multichannel Retail for Three-dimensional Virtual Worlds and Two-dimensional Websites". figshare. https://hdl.handle.net/2134/38167. 
Accepted version for the 11th Web Science Conference 2019, Boston USA

\title{
The Six Relative Advantages in Multichannel Retail for Three-Dimensional Virtual Worlds and Two-Dimensional Websites
}

\author{
Alex Zarifis \\ Business School, University of Mannheim \\ Mannheim \\ azarifis@mail.uni-mannheim.de
}

\begin{abstract}
Multichannel retail is now prevalent with retailers and consumers utilizing a number of channels in parallel or in some instances in an interconnected way. There is a degree of understanding on what each channel can offer but the Relative Advantage of each channel in relation to the others is less understood. This research evaluates the Relative Advantage between the three channels of three-dimensional Virtual Worlds, two-dimensional websites and offline retail stores. The consumer's preferences across the three channels were distinguished across six Relative Advantages. The three channels were then compared across the six Relative Advantages identified. Participants showed a preference for offline and $2 \mathrm{D}$ in most situations apart from enjoyment, entertainment, sociable shopping, the ability to reinvent yourself, convenience and institutional trust where the Virtual Worlds were preferred.
\end{abstract}

\section{CCS CONCEPTS}

- Applied computing $\rightarrow$ Electronic commerce $\rightarrow$ Online shopping

KEYWORDS: Virtual Worlds; Virtual reality; e-Commerce; Multichannel; Trust.

\section{Introduction}

Three retail channels are compared to evaluate their respective Relative Advantage (RA). The first channel is the physical 'brick and mortar' retail stores, the second channel is websites that are navigated and display information in two dimensions (2D websites) and the third channel is three dimensional online environments known as Virtual Worlds (VW) [2]. The foundation of this research is Choudhury and Karahanna [5] that compared two channels. Six RAs were identified that capture the consumer's preferences across the three channels. These six RAs serve as categories of the many specific issues that influence the consumer's behavior across multiple channels. Purchases in 2D websites are increasing, potentially surpassing physical 'brick and mortar' shops in a few years. Physical, offline, shops still play a significant role and have advantages that 2D websites find difficult to replicate.

VWs have been with us for over a decade but their potential to replicate features of the physical world has not been fully realized. Their adoption is at low levels and it has not yet reached a majority in the diffusion of innovation curve [27]. There is however renewed interest in this area [6] with major technology companies starting to drive adoption [33, 36], in a number of ways including augmented reality and virtual reality headsets. It is therefore useful to explore their advantages in relation to each other, as perceived by the consumer. A better understanding of the relationship between the three channels will support organizations in developing their multichannel or omni-channel approach by integrating the channels in a way that fully utilizes their RAs. It will also support the optimization of the many information systems that enable these processes.

The first objective to explore was whether a RA of VWs compared to the 2D navigation Internet, was the aspects of offline retail that it includes, that do not exist in the $2 \mathrm{D}$ websites. The second objective explores the same topic between the other pair: Could a RA of VWs over offline be aspects of 2D navigation websites that it includes that are not included in the offline retail environment? The third objective was to explore whether the consumer changes the way a VW is used across the different stages of the purchase. Furthermore, if the consumer changed the way a VW is used across the steps of purchasing process, it would 
be useful to evaluate whether the significance of the dimensions identified in Choudhury and Karahanna [5] also changed. The fourth objective was to evaluate whether the consumer's usage of VW is different for simple and complex products. The consumer approaches a purchase of a simple and a complex product differently and it is therefore possible that some characteristics of VWs are valued differently in these different processes. The fifth objective was to explore whether VWs may have the RA of a higher degree of institutional trust compared to the 2D websites. The sixth objective was to explore whether a RA of VWs compared to $2 \mathrm{D}$ websites for e-commerce is that they offer a higher level of enjoyment. The next section offers an overview of the literature on multichannel retail followed by the methodology applied in this research. The fourth section covers the qualitative findings and identifies the issues to be further evaluated. The fifth section presents the quantitative findings followed by the discussion and finally the conclusion.

\section{Multichannel Retail}

Evaluating multichannel retail presents a formidable challenge as it requires an understanding of a number different channels, each with their particular characteristics. These channels can be utilized independently or in an interrelated way. Identifying the aspects that are important to the consumer and the aspects that give each channel unique characteristics and a RA is far from simple.

Most research in this area compares traditional brick and mortar shops and 2D websites. The third channel that should be incorporated into the discussion on multichannel retail is VWs. VWs are online three dimensional physically persistent environments where people inhabit and interact with other people, software agents and objects through the use of avatars [18]. Social virtual worlds are VWs where there are no specific goals, sometimes referred to as 'free-form' [13]. There are VWs that focus on gaming but may have a social element such as massively multiplayer online role-playing games (MMORPG) and others that focus on the social element but may include games such as Twinity, There.com, Second Life and Active Worlds. People use VWs for several reasons, some of which are different to why they use 2D websites. Five themes that motivate people to use VWs are self-therapy, instant pleasures, avoiding social norms, selfexpression and the appeal of exploration and novelty [25]. Shen and Eder [32] identified perceived usefulness and perceived enjoyment as strong reasons for VW adoption. In addition to these issues that seem to be more significant in VWs there is also the importance of virtual communities [18]. Gammoh et al.[9] found evidence that avatars as sales agents can enhance the consumer's satisfaction with the retailer, make the consumer perceive the product more positively and be more willing to make a purchase. Products can be physical such as shoes [8], virtual products such as virtual shoes, services that are utilized within the VWs such as hosting a conference and services utilized outside of them such as financial services. The sale of virtual products can be referred to as v-commerce [16]. Cagnina and Poian [3] identified the use and limitations of the previous models and attempted to capture the value drivers of each VW and how this impacted the value chain of the business models within them. Therefore, Cagnina and Poian [3] can be used to bring the literature of business models and that of VW together.

An important consideration for the consumer online, whether in two or three-dimensional environments is trust. Trust is central to collaborating online [4] and particularly business to consumer (B2C) e-commerce where a financial transaction is made [31]. It can be separated into two constituent parts, 'trusting beliefs' and 'trusting intention' [22]. Institutional trust is the consumer's trust in the structures in place that aid a positive outcome for the consumer [22]. For B2C, Pavlou and Gefen [26] consider it to be the buyers perception that effective third-party institutional mechanisms are in place to support a successful transaction. These third-party mechanisms vary from 'weak' ones like transaction facilitation offered by PayPal, certification such as Verisign and enabling feedback to 'strong' ones such as the legal framework [26]. The mechanisms that form an institution can also be formal or informal. An example of a formal institution is the legal framework already mentioned, and examples of informal institutions are communities or group ties [35]. Some constituent parts of institutional trust may be common across all channels such as paying with a specific bank card while others are specific to a channel such as the consumer protection in the specific country where a brick and mortar shop is situated.

One of the behaviors identified in multichannel research is seeking information on one channel and purchasing on another [14]. This has been referred to as cross channel free-riding and is clearly not to the benefit of the organization not rewarded [14]. There is evidence that the consumer prefers different channels for different actions [30]. Searching for information about a purchase such as price, and making a purchase have a distinct nature and different channels may be preferred for each stage [28]. Each channel is found to have different utility [28]. Additional distinctions are examining and picking up the product that is being considered for purchase [12].

Discussion of multiple channels inevitably leads to strategy and business models [21]. Synergies are often sought out when making strategic decisions but in multichannel research they are a priority [20] and must be based on the customer's perspective [29]. With all strategic decisions resource allocation is important and this is also the case in multichannel strategies [28]. Once each channel's advantages and disadvantages are understood to a high granularity an organization can move on to assessing which ones to use and how to use them together. For example, would an organization want to offer the same functionality and products through different channels or would the organization adapt their presence to each channel to utilize that channel's characteristics? Making these choices correctly can lead to an increase in customers and market share [12].

The multitude of strategies can be perceived on a spectrum from entirely homogenized channels to entirely separate offerings. Some examples of multi-channel strategies with less homogenized offerings are: Offering more products on the online shop than the bricks and mortar shop because a company may have one warehouse that serves the online orders and that makes stock 
management easier and cheaper than in the case of the bricks and mortar shops. A second strategy is to offer more specialized products that sell in smaller numbers online [12]. If the strategy would involve having a different approach to each channel, then it may also incorporate an attempt to migrate from one channel to the other [7].

A more homogenous strategy would attempt to achieve a more coherent user experience, brand, product and service offering across channels regardless of their particularities [37]. This coherence also reduces the risk of causing confusion and dissatisfaction with different prices, products, services [19] and return policies including returns to different channels. It is clear that choosing the right point on the spectrum between homogenization and an entirely different offering is important and far from straight forward [38]. This process has been referred to as harmonization of the channel and has been considered to be a craft [39]. The word craft was chosen to suggest this is not a problem for which one solution can be offered. A number of decisions, supported with a greater understanding of the nuances involved is necessary. Choudhury and Karahanna [5] explored the RA of two electronic channels as illustrated in figure 1. Based on the theory of diffusion of innovation [27] it assumes that a new channel, as with any innovation, must offer a RA in order for consumers to adopt it. Adding VWs and exploring the RA of three retail channels would be useful.

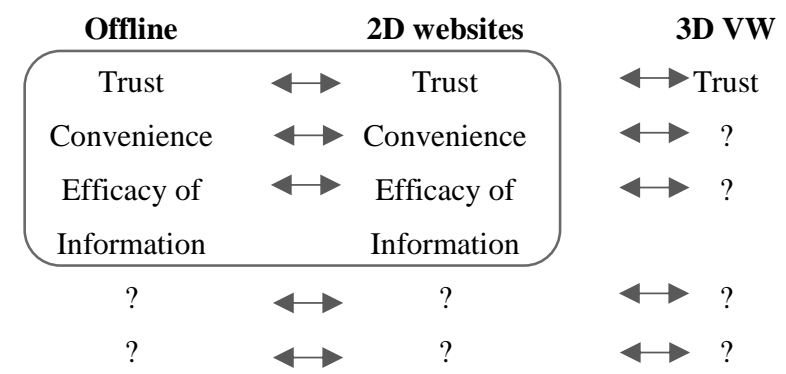

Figure 1. Current literature and research gap

\section{Method}

\subsection{Data Collection}

The epistemological approach was critical realist using mixed methods. The qualitative stage involved four focus groups with three to five participants and twelve interviews. This was followed by a quantitative survey that was used to evaluate the consumer's beliefs on the six objectives identified in the qualitative stage. The survey allowed the participant to rank the three channels according to preference on a number of questions related to the six objectives. The questions emerged from the initial qualitative focus groups and interviews. Each question evaluated an important aspect of each RA and together with other related questions they evaluated the RA itself. The survey applied random sampling with a target of 550 participants. A message was sent from within the VW including a link to the survey to potential participants that met the requirements set. The first requirement was for a minimum of six months of experience in a VW. This could be verified by checking when an avatar was created. The second requirement was for the participants to have made a purchase of a product in the VW. This was checked in question 10 and $97 \%$ stated that they had made a purchase in a VW. The participants were also paid and vetted so they were considered responsible and knowledgeable.

Fifty-nine questions were compulsory closed ended questions where the participant answered by selecting a point on a scale that represented their views. This was done mostly by using a slider enabling the data to fit a Gaussian scale better than if they had to choose from a limited set of options such as a five-point Likert scale. The first 12 questions enquired about the participant and their use of VWs. The next eight covered how long, how intensely and for what purpose the participant used VWs. After those demographic questions the first section of the main survey had ten questions covering different aspects related to purchasing products from VWs. The feedback was given on a scale from 'strongly disagree', minus fifty, to 'strongly agree', fifty, using a slider. The second section of the main part of the survey focused on the RA of the three channels by directly comparing them. There were fourteen questions about different aspects of purchasing a product. Under each question there were three sliders one for each retail channel, offline, online 2D website and VWs. The participant chose the degree to which they agreed with the statement in the context of each channel. The scale was the same as in section one. Surveys that were not completed were taken out of the data set. Therefore 616 participants can be considered to have taken the survey.

\subsection{Data Analysis}

The qualitative data was analyzed using open coding to clarify the issues that would be further evaluated in the quantitative part. The quantitative analysis was on the responses to the survey. The analysis would compare the participants' preferences between three retail channels across several issues identified in the extensive exploratory phase that involved focus groups and interviews. The mean, the standard of deviation and ANOVA were used to explore the data. For the second and third sections the analysis compared between pairs of channels using the t-test to evaluate whether the channels are perceived differently or not, in relation to the given issue.

The second section had three scales for each question. Each scale allowed the participant to show how much they valued one of the three channels for the given issue. The three scales were divided into three pairs to carry out the two-group t-test. This is both statistically and logically sound. The purpose is to identify an RA of one channel compared to another. The pairs were the first scale with the second, the first with the third and the second with the third. The two means that resulted from the responses to the two scales were compared using the t-test to determine whether those means represented different populations. The third section had two scales for each question only comparing two channels. An example of a possible insight from this analysis could be that 
customers find buying offline more convenient than buying from a VW.

To limit the risk of type one errors the p-value for this research was set at 0.025 . When multiple t-tests are used together the risk of type one errors increases. The analysis in this research implements the t-tests separately comparing two channels. If the ttests in this section were combined to create an order of preference for all three channels the risk of type one errors would increase. The two-sample paired t-test was applied to questions 24 to 37 . The one sample t-test was applied to questions 38 to 59 . The analysis provides several findings beyond the t-test value. The key results of the t-test are presented and discussed in the next two sections.

\section{Findings}

\subsection{The Relative Advantages of Multichannel Retail to be Evaluated}

The RAs identified from the literature were explored and clarified by initial qualitative analysis before they were verified with quantitative analysis. VWs incorporate some characteristics from the two other channels, but they offer a unique combination of these characteristics. The first two RAs of VWs for retail are based on the characteristics they draw from the $2 \mathrm{D}$ websites and the 'bricks and mortar' environment.

The first objective explored in the qualitative stage was the RA of VWs compared to 2D websites. Many participants' responses were on this objective and subcategories were identified. These were primarily enjoyment, which will be discussed in more detail in the sixth RA to be explored; social shopping, a richer and more emotive 3D environment, 'face to face', the shopping assistant and to a lesser extent location. In relation to which channel was most emotive, all participants considered the offline environment to be first, which is understandable, and most considered VWs to be more emotive than $2 \mathrm{D}$ websites. Therefore, based on the exploratory qualitative stage:

RA1: A relative advantage of VWs to $2 D$ websites for $e$ commerce, are aspects of the offline environment that VWs include, that do not exist in the $2 D$ websites.

The second objective in the qualitative stage, explored what the RA of VWs is, compared to offline. The nature of the information systems of VWs operating on the Internet guarantees that they will contain some of the Internet's benefits compared to offline. It is therefore not controversial since it is based directly on the functionality of the information systems and not its implementation by a specific organization. When the issue in question results from a specific implementation of a technology the user's perceptions can have greater variety. The data collected on this issue is nevertheless useful as it illustrates this point with empirical evidence and more detail. There was extensive interest from the participants on this issue and four related subcategories of this RA were identified as convenience, speed, 24-7 availability and global reach. Therefore, based on the qualitative stage:
RA2: A relative advantage of $V W$ s for the consumer compared to offline, are $2 D$ website features that VWs include, that are not included in the offline environment.

Choudhury and Karahanna [5] suggested that a consumer would adopt a new channel only if it was perceived to offer an advantage over existing channels. This argument is built on the theory of diffusion of innovation [27]. The third objective states that the 'variable' dimension of RA, will vary across the 'variable' of the stages of the purchasing process. If a consumer prefers a different channel for each stage, this would be a strong indication of the benefit of organizations utilizing a multichannel approach. There was evidence that participants had specific beliefs on each channel's advantages and disadvantages and chose the one they would use for a given task accordingly. They often did not have an outright favorite for all the stages. What could be considered surprising is that no participant chose the same channel for all the stages. Therefore, based on the qualitative stage:

RA3: The consumer may vary their intended usage of VWs across the different stages of the purchase process because the significance of the dimensions may vary across those stages.

The nature of gathering information and making a purchase for a complex product in comparison to a simple product is different [5]. Because of this, the nature of how the technology and the other aspects of a channel are used, is different. Therefore, the variables to compare are consumer usage, product complexity and purchase stages. Most participants considered the 2D websites and offline as best for simple products. For complex products, overall, most participants considered the offline environment as the best. Some considered two dimensional websites better because you can get more information in a shorter space of time. The other reason given for preferring $2 \mathrm{D}$ was that they preferred to absorb information in text form. There is of course information in twodimensional text in VWs but there is usually some navigation involved before it can be viewed. Those that considered VWs to be better than $2 \mathrm{D}$ websites, believed this primarily because of the shopping assistant. Therefore, based on the qualitative stage:

RA4: The consumer's usage of VWs may be different for simple and complex products.

Based on the literature on trust as it has been defined and modelled by McKnight et al. [23], institutional trust has been identified as the most relevant aspect of trust. This is in agreement with Choudhury and Karahanna [5]. When considering institutional trust for VWs it is important to clarify what the institution being considered is. For this study the institution is a specific VW, as opposed to VWs in general. There were four types of responses from the participants. The most common was to group the two dimensional and three dimensional together because the underlying technology was the same. There were some that trusted two dimensional websites, the most common reason being that it was more established, and you can read feedback. 


\begin{tabular}{|c|c|c|c|c|c|c|c|}
\hline & Channel & $\begin{array}{l}\text { RA 1 } \\
\text { Aspects } \\
\text { of } \\
\text { offline }\end{array}$ & $\begin{array}{l}\text { RA 2 } \\
\text { Aspects } \\
\text { of 2D } \\
\text { websites }\end{array}$ & $\begin{array}{l}\text { RA } 3 \\
\text { Vary } \\
\text { usage as } \\
\text { RA of } \\
\text { issues } \\
\text { varies } \\
\end{array}$ & $\begin{array}{l}\text { RA } 4 \\
\text { Usage } \\
\text { different for } \\
\text { simple and } \\
\text { complex } \\
\text { products }\end{array}$ & $\begin{array}{l}\text { RA } 5 \\
\text { Level of } \\
\text { institutional } \\
\text { trust }\end{array}$ & $\begin{array}{l}\text { RA } 6 \\
\text { Level of } \\
\text { enjoyment }\end{array}$ \\
\hline & $\stackrel{\mathscr{E}}{\leftrightarrows}$ & $\begin{array}{l}\text { High or } \\
\text { low? }\end{array}$ & $\begin{array}{l}\text { High or } \\
\text { low? }\end{array}$ & $\begin{array}{l}\text { High or } \\
\text { low? }\end{array}$ & High or low? & High or low? & $\begin{array}{l}\text { High or } \\
\text { low? }\end{array}$ \\
\hline \multirow[t]{2}{*}{$\begin{array}{l}\text { Consu } \\
- \text { mer }\end{array}$} & 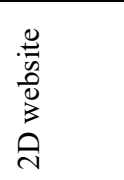 & $\begin{array}{l}\text { High or } \\
\text { low? }\end{array}$ & $\begin{array}{l}\text { High or } \\
\text { low? }\end{array}$ & $\begin{array}{l}\text { High or } \\
\text { low? }\end{array}$ & High or low? & High or low? & $\begin{array}{l}\text { High or } \\
\text { low? }\end{array}$ \\
\hline & 3 & $\begin{array}{l}\text { High or } \\
\text { low? }\end{array}$ & $\begin{array}{l}\text { High or } \\
\text { low? }\end{array}$ & $\begin{array}{l}\text { High or } \\
\text { low? }\end{array}$ & High or low? & High or low? & $\begin{array}{l}\text { High or } \\
\text { low? }\end{array}$ \\
\hline
\end{tabular}

Figure 2. Three channels and the six Relative Advantages

There were some that preferred the VWs sighting the payment system. Some highlighted how a VW as an 'institution' influenced 'institutional trust' positively. Some participants noted that the owner of the VW informs users about retailers that are not trustworthy. This illustrates how the fact that a VW is owned by a specific organization has the potential to cultivate greater institutional trust. That logic was the reason why this issue was identified as an area to investigate. Therefore, based on the qualitative stage:

RA5: VWs may have the RA of more institutional trust for the consumer compared to the $2 D$ websites.

One additional RA of VWs for retail is that of enjoyment and entertainment. Some participants linked the higher level of enjoyment directly to the 3D environment. Therefore, based on the qualitative stage the sixth RA was put forward. Figure 2 illustrates how insight into the six RAs can support the multichannel strategy.

RA6: A RA for the consumer of VWs to $2 D$ websites, is that they offer a higher level of enjoyment.

Based on the qualitative findings it is also suggested that the model put forward by Choudhury and Karahanna [5] could be extended. The model by Choudhury and Karahanna [5], stated that for the purpose of assessing the RA of a channel for retail: Relative Advantage $($ RA) $=$ Convenience + Trust + Efficacy of Information. The initial qualitative stage supported the importance of Convenience and Efficacy of Information. There was evidence supporting that institutional trust (RA5) was the type of trust most relevant and that enjoyment (RA6) was important in the choice of channel, particularly when the consumer considered VWs along with 2D websites and offline stores. The findings of RA1, 2, 3 and 4 are also relevant to the model. Therefore, the model can be extended as follows: RA of a retail channel $=$ Convenience +
Institutional Trust + Efficacy of Information + Enjoyment + RA of unique channel functionalities $+\mathrm{RA}$ in specific purchasing stage + RA for specific type of product.

\subsection{Channel Comparison on Key Variables}

4.2.1 Analysis of Questions Comparing Three Channels. A summary of the results of this section is provided in table 1 . The first question for which the two-sample dependent t-test was applied was question 24. For question 24 the vignette stated: 'I would learn all I need to know about a product from this channel', when comparing offline $(\mathrm{M}=66.46, \mathrm{SE}=0.97)$ to online $2 \mathrm{D}$ $(\mathrm{M}=71.18, \mathrm{SE}=0.85), \mathrm{t}(607)=-4.49, \mathrm{p}<0.025, \mathrm{r}=0.18$, participants on average considered the latter to be preferable out of the two to a significant degree. When comparing offline to VWs, $(M=70.84$, $\mathrm{SE}=0.93), \mathrm{t}(607)=-3.52, \mathrm{p}<0.025, \mathrm{r}=0.14$, participants on average considered the latter to be significantly preferable. When comparing online $2 \mathrm{D}$ to $\mathrm{VWs}, \mathrm{t}(607)=0.34, \mathrm{p}>0.025, \mathrm{r}=0.01$, participants on average considered the former to

be preferable. All three however had a very small effect size accounting for less than $1 \%$ of total variance. The questions from 24 to 37 had this format and were evaluated in this way.

4.2.2 Analysis of Questions Comparing Two Channels. Questions 38 to 59 also discussed RA like the ones above. However, each question only covered two channels. The 38th question will be used as an example to illustrate this: '... I can do it with my friends, so it is more sociable'. If the average response was at 'neither' this would indicate that there was no difference in the perception of the two channels. A positive average would indicate a preference to VWs. The results are summarized in table 2 and discussed in the following section. 


\begin{tabular}{|c|c|c|c|c|c|c|c|c|c|c|c|c|c|c|c|}
\hline \multirow[t]{3}{*}{ Question } & \multicolumn{7}{|c|}{ Comparing offline to online 2D } & \multicolumn{5}{|c|}{ Comparing offline to VWs } & \multicolumn{3}{|c|}{$\begin{array}{l}\text { Comparing online 2D to } \\
\text { VW }\end{array}$} \\
\hline & \multicolumn{2}{|c|}{ Offline } & \multicolumn{2}{|c|}{ Online 2D } & \multirow[b]{2}{*}{$t(607)$} & \multirow[b]{2}{*}{$\mathbf{p}$} & \multirow[b]{2}{*}{$\mathbf{r}$} & \multicolumn{2}{|c|}{ VW } & \multirow[b]{2}{*}{$\mathbf{t}(607)$} & \multirow[b]{2}{*}{$\mathbf{p}$} & \multirow[b]{2}{*}{$\mathbf{r}$} & \multirow[b]{2}{*}{$t(607)$} & \multirow[b]{2}{*}{$\mathbf{p}$} & \multirow[b]{2}{*}{$\mathbf{r}$} \\
\hline & M & SE & M & SE & & & & M & SE & & & & & & \\
\hline $\begin{array}{l}\text { 24. I would learn all I need to know about a } \\
\text { product from this channel }\end{array}$ & 66.46 & 0.97 & 71.18 & 0.85 & -4.49 & $<0.025$ & 0.18 & 70.84 & 0.93 & -3.52 & $<0.025$ & 0.14 & 0.34 & $>0.025$ & 0.01 \\
\hline $\begin{array}{l}\text { 25. I would find it convenient to purchase car } \\
\text { insurance from this channel }\end{array}$ & 65.76 & 1.14 & 58.87 & 1.17 & 4.89 & $<0.025$ & 0.19 & 40.30 & 1.23 & 15.17 & $<0.025$ & 0.52 & 14.90 & $<0.025$ & 0.52 \\
\hline $\begin{array}{l}\text { 26. I would find it convenient to purchase a } \\
\text { book from this channel }\end{array}$ & 73.87 & 1.04 & 74.70 & 0.98 & -0.96 & $>0.025$ & 0.04 & 57.82 & 1.18 & 11.84 & $<0.025$ & 0.43 & 13.72 & $<0.025$ & 0.49 \\
\hline $\begin{array}{l}\text { 27. I would feel confident purchasing the car } \\
\text { insurance policy through this channel }\end{array}$ & 71.42 & 1.15 & 57.18 & 1.20 & 11.04 & $<0.025$ & 0.41 & 37.36 & 1.21 & 20.57 & $<0.025$ & 0.64 & 15.99 & $<0.025$ & 0.54 \\
\hline $\begin{array}{l}\text { 28. I would feel confident purchasing a book } \\
\text { through this channel }\end{array}$ & 78.80 & 1.04 & 75.13 & 1.01 & 4.62 & $<0.025$ & 0.18 & 57.35 & 1.24 & 15.39 & $<0.025$ & 0.53 & 14.42 & $<0.025$ & 0.51 \\
\hline $\begin{array}{l}\text { 29. To determine what I want to buy I like } \\
\text { using this channel }\end{array}$ & 72.17 & 0.98 & 78.43 & 0.90 & -6.92 & $<0.025$ & 0.27 & 60.11 & 1.13 & 8.53 & $<0.025$ & 0.33 & 14.03 & $<0.025$ & 0.49 \\
\hline $\begin{array}{l}\text { 30. To purchase a product I like using this } \\
\text { channel }\end{array}$ & 76.63 & 0.95 & 75.81 & 0.92 & 0.91 & $>0.025$ & 0.04 & 59.27 & 1.11 & 12.23 & $<0.025$ & 0.44 & 13.14 & $<0.025$ & 0.47 \\
\hline $\begin{array}{l}\text { 31. For after sales service I like using this } \\
\text { channel }\end{array}$ & 72.74 & 1.01 & 68.87 & 0.98 & 3.25 & $<0.025$ & 0.13 & 57.25 & 1.11 & 10.14 & $<0.025$ & 0.38 & 9.06 & $<0.025$ & 0.35 \\
\hline $\begin{array}{l}\text { 32. For a simple product that is always the } \\
\text { same and does not involve contracts and } \\
\text { negotiation such as a book I would use this } \\
\text { channel }\end{array}$ & 75.93 & 0.99 & 77.21 & 0.96 & -1.44 & $>0.025$ & 0.06 & 63.09 & 1.11 & 9.41 & $<0.025$ & 0.36 & 12.47 & $<0.025$ & 0.45 \\
\hline $\begin{array}{l}\text { 33. For a complex product that is not always } \\
\text { the same and may need negotiation such as car } \\
\text { insurance, I would prefer this channel }\end{array}$ & 77.10 & 1.07 & 57.57 & 1.15 & 13.72 & $<0.025$ & 0.49 & 41.71 & 1.19 & 20.68 & $<0.025$ & 0.64 & 12.90 & $<0.025$ & 0.46 \\
\hline $\begin{array}{l}\text { 34. I enjoy shopping on this channel for its } \\
\text { own sake, not just for the items I may have } \\
\text { purchased }\end{array}$ & 70.25 & 1.01 & 69.85 & 0.96 & 0.41 & $>0.025$ & 0.02 & 69.85 & 1.05 & 0.75 & $>0.025$ & 0.03 & 0.52 & $>0.025$ & 0.02 \\
\hline $\begin{array}{l}\text { 35. This channel doesn't just sell products-it } \\
\text { entertains me }\end{array}$ & 62.17 & 1.02 & 64.88 & 0.96 & -2.85 & $<0.025$ & 0.11 & 76.61 & 0.97 & -11.87 & $<0.025$ & 0.43 & -11.05 & $<0.025$ & 0.41 \\
\hline $\begin{array}{l}\text { 36. Shopping from this channel "gets me away } \\
\text { from it all" }\end{array}$ & 58.10 & 1.00 & 61.00 & 0.93 & -2.71 & $<0.025$ & 0.11 & 69.50 & 1.05 & -9.35 & $<0.025$ & 0.35 & -8.49 & $<0.025$ & 0.33 \\
\hline $\begin{array}{l}\text { 37. I find this channel is not as good as other } \\
\text { channels at informing me about the product }\end{array}$ & 50.80 & 1.06 & 48.79 & 1.01 & 1.80 & $>0.025$ & 0.07 & 56.82 & 0.99 & -4.21 & $<0.025$ & 0.17 & -6.67 & $<0.025$ & 0.26 \\
\hline
\end{tabular}

Table 1. Comparing the channels in section 2 of the survey

\subsection{The Six Relative Advantages of Multichannel Retail}

4.3.1 Findings Related to the First Relative Advantage. The first objective stated 'a RA of VWs compared to the $2 \mathrm{D}$ websites is aspects of offline retail VWs include that do not exist in the 2D websites'. The issues relevant to this were primarily enjoyment, social shopping, a richer and more emotive 3D environment, 'face to face' and the shopping assistant, and to a lesser extent location. There was no preference for the shopping assistant in comparison to offline on average. There was however significant support that the salesperson was a RA compared to $2 \mathrm{D}$ websites. The findings therefore suggest that, on average, the aspect from offline of having a shopping assistant, is a RA of VWs compared to the 2D internet. For navigation, in the quantitative section, VWs were considered to have an advantage over both offline and 2D websites. It was considered a greater RA when compared to $2 \mathrm{D}$ websites. Therefore, the findings suggest that on average the aspect that offline and VWs share, compared to navigation in 2D is a RA of VWs compared to $2 \mathrm{D}$ websites. For sociability, the quantitative analysis indicated a significant preference for VWs over 2D websites with a medium effect. Therefore, it can be concluded that sociable shopping is a RA of shopping in VWs in comparison to 2D navigation websites. In terms of location VWs were preferred significantly but with a medium effect to $2 \mathrm{D}$ websites. In the context of $\mathrm{B} 2 \mathrm{C}$ e-commerce in VWs location refers to how the virtual shops are located in the virtual environment. This could be considered the virtual geography. The last relevant issue was the ability to reinvent yourself and be someone you are not. The results showed that the ability to reinvent oneself was a RA of shopping in VWs compared to 2D websites. Overall, the findings related to this RA support the increased sense of involvement VWs can offer in comparison to 2D websites [1].

4.3.2 Findings Related to the Second Relative Advantage. The second objective stated, 'a relative advantage of VWs for the consumer compared to offline, are 2D website features that VWs include, that are not included in the offline environment'. These were found to be convenience, speed, twenty-four-seven availability, global reach and additional information such as reviews and profiles. The participants were asked to compare the channels based on which one would enable them to learn all they wanted to know about the product. $2 \mathrm{D}$ navigation websites were preferred to both other channels. VWs were preferred to offline by some margin. This was an indication that features that VWs and 2D websites included, but were missing from offline, were considered a RA. In terms of convenience, VWs were at a disadvantage to both other channels.

Issues that arose in the qualitative section such as twenty-fourhour availability, access from the convenience of your home, on average were outweighed by the other conveniences of offline and inconveniences of VWs.

4.3.3 Findings Related to the Third Relative Advantage. The third objective stated 'consumers vary their intended usage of VWs across the different stages of the purchase process because the significance of the dimensions of RA may vary across those stages'. The foundation that this research builds on [5], concluded that there was evidence of three stages in the purchasing process. 


\begin{tabular}{|c|c|c|c|c|c|c|}
\hline Question & $\begin{array}{l}\text { Compared } \\
\text { to VWV }\end{array}$ & $\mathbf{M}$ & $\begin{array}{l}\text { Stand. } \\
\text { error } \\
\text { mean }\end{array}$ & $\begin{array}{l}\text { t- } \\
\text { statistic }\end{array}$ & $\begin{array}{l}\mathrm{P} \\
\text { (sign.) }\end{array}$ & $\begin{array}{l}R \\
\text { (e.s.) }\end{array}$ \\
\hline $\begin{array}{l}\text { 38. A relative advantage of shopping in a VW compared to } \\
\text { offline shopping is that I can do it with my friends, so it is more } \\
\text { sociable }\end{array}$ & offline & 61.19 & 1.08 & 9.44 & $<0.025$ & 0.36 \\
\hline $\begin{array}{l}\text { 39. A relative advantage of shopping in a VW compared to a } \\
2 \mathrm{D} \text { navigation website is that I can do it with my friends, so it } \\
\text { is more sociable }\end{array}$ & 2D web & 66.80 & 1.01 & 15.55 & $<0.025$ & 0.53 \\
\hline $\begin{array}{l}\text { 40. A relative advantage of shopping in a VW compared to } \\
\text { offline shopping is that there is a shop assistant and you can } \\
\text { talk to them "face to face" }\end{array}$ & offline & 50.67 & 1.08 & -0.31 & $>0.025$ & 0.01 \\
\hline $\begin{array}{l}\text { 41. A relative advantage of shopping in a VW compared to a } \\
2 \text { D navigation website is that there is a shop assistant and you } \\
\text { can talk to them "face to face" }\end{array}$ & $2 \mathrm{D}$ web & 60.38 & 1.02 & 9.21 & $<0.025$ & 0.35 \\
\hline $\begin{array}{l}\text { 42. A relative advantage of shopping in a VW compared to } \\
\text { offline shopping is the convenience and speed }\end{array}$ & offline & 69.03 & 0.95 & 19.10 & $<0.025$ & 0.61 \\
\hline $\begin{array}{l}\text { 43. A relative advantage of shopping in a VW compared to a } \\
2 \mathrm{D} \text { navigation website is the convenience and speed }\end{array}$ & $2 \mathrm{D}$ web & 59.02 & 1.02 & 7.85 & $<0.025$ & 0.30 \\
\hline $\begin{array}{l}\text { 44. A relative advantage of shopping in a VW is the payment } \\
\text { method which is easy to use compared to offline shopping }\end{array}$ & offline & 58.68 & 1.15 & 6.68 & $<0.025$ & 0.26 \\
\hline $\begin{array}{l}\text { 45. A relative advantage of shopping in a VW is the payment } \\
\text { method which is easy to use compared to a } 2 \mathrm{D} \text { navigation } \\
\text { website }\end{array}$ & 2D web & 59.97 & 1.09 & 8.20 & $<0.025$ & 0.32 \\
\hline $\begin{array}{l}\text { 46. A relative advantage of shopping in a VW is the payment } \\
\text { method which is safe compared to offline shopping }\end{array}$ & offline & 50.17 & 1.13 & -7.31 & $>0.025$ & 0.03 \\
\hline $\begin{array}{l}\text { 47. A relative advantage of shopping in a VW is the payment } \\
\text { method which is safe compared to a } 2 \mathrm{D} \text { navigation website }\end{array}$ & 2D web & 56.06 & 1.05 & 4.81 & $<0.025$ & 0.19 \\
\hline $\begin{array}{l}\text { 48. A relative advantage of shopping in a VW is the after sales } \\
\text { service which is good compared to offline shopping }\end{array}$ & offline & 52.91 & 1.01 & 1.90 & $>0.025$ & 0.08 \\
\hline $\begin{array}{l}\text { 49. A relative advantage of shopping in a VW is the after sales } \\
\text { service which is good compared to a } 2 \mathrm{D} \text { navigation website }\end{array}$ & $2 \mathrm{D}$ web & 56.79 & 0.94 & 6.16 & $<0.025$ & 0.24 \\
\hline $\begin{array}{l}\text { 50. A relative advantage of shopping in a VW compared to } \\
\text { offline shopping is the way you navigate the world as it } \\
\text { enhances the browsing experience }\end{array}$ & offline & 66.08 & 1.00 & 15.15 & $<0.025$ & 0.52 \\
\hline $\begin{array}{l}\text { 51. A relative advantage of shopping in a VW compared to a } \\
2 \mathrm{D} \text { navigation website is the way you navigate the world as it } \\
\text { enhances the browsing experience }\end{array}$ & 2D web & 70.10 & 0.91 & 21.00 & $<0.025$ & 0.65 \\
\hline $\begin{array}{l}\text { 52. A relative advantage of shopping in a VW compared to } \\
\text { offline shopping is that good stores are located near each other }\end{array}$ & offline & 59.16 & 1.02 & 8.00 & $<0.025$ & 0.31 \\
\hline $\begin{array}{l}\text { 53. A relative advantage of shopping in a VW compared to a } \\
\text { 2D navigation website is that good stores are located near each } \\
\text { other }\end{array}$ & 2D web & 57.58 & 1.01 & 6.53 & $<0.025$ & 0.26 \\
\hline $\begin{array}{l}\text { 54. A relative advantage of shopping in a VW compared to } \\
\text { offline shopping is that I can become something I am not in real } \\
\text { life, reinvent myself }\end{array}$ & offline & 74.00 & 0.99 & 23.29 & $<0.025$ & 0.69 \\
\hline $\begin{array}{l}\text { 55. A relative advantage of shopping in a VW compared to a } \\
2 \mathrm{D} \text { navigation website is that I can become something I am not } \\
\text { in real life, reinvent myself }\end{array}$ & 2D web & 69.21 & 1.05 & 17.35 & $<0.025$ & 0.58 \\
\hline $\begin{array}{l}\text { 56. A relative advantage of shopping in a VW compared to } \\
\text { offline shopping is that I can purchase virtual versions of real- } \\
\text { life products at a much lower price }\end{array}$ & offline & 68.13 & 1.01 & 17.05 & $<0.025$ & 0.57 \\
\hline $\begin{array}{l}57 \text {. A relative advantage of shopping in a VW compared to a } \\
2 \mathrm{D} \text { navigation website is that I can purchase virtual versions of } \\
\text { real-life products at a much lower price }\end{array}$ & 2D web & 66.55 & 1.00 & 15.59 & $<0.025$ & 0.54 \\
\hline $\begin{array}{l}\text { 58. A relative advantage of shopping in a VW compared to } \\
\text { offline shopping is that I can purchase virtual product that are } \\
\text { instantly delivered }\end{array}$ & offline & 75.68 & 0.95 & 26.00 & $<0.025$ & 0.73 \\
\hline $\begin{array}{l}59 \text {. A relative advantage of shopping in a VW compared to a } \\
2 \mathrm{D} \text { navigation website is that I can purchase virtual product that } \\
\text { are instantly delivered }\end{array}$ & 2D web & 75.55 & 0.92 & 26.60 & $<0.025$ & 0.73 \\
\hline
\end{tabular}

Table 2. Comparing VWs to the other channels in the survey

For requirements determination, the quantitative analysis found that 2D was more popular than both the other channels. Offline was preferred to VWs. 2D navigation websites are ideal for searching and viewing information on products, while offline products can be physically handled, so this result can be considered logical. For the purchasing stage, offline and 2D websites had no significant difference between them with VWs having a significant difference and effect. Therefore, VWs were at a disadvantage for both stages. The change in the preference, for offline and 2D websites, between this stage and the one preceding it, illustrates the distinct perceptions of the value of each channel.
For the last stage, after sales service, offline was more popular than both other channels and 2D websites were more popular than VWs. The margin however between VWs and the other channels was much smaller for this stage. This is an indication that VWs are more useful for after sales service than the other two stages.

4.3.4 Findings Related to the Fourth Relative Advantage. The fourth issue stated that a consumer's purchasing behavior in VWs is different for simple and complex products. The quantitative analysis for complex products found that offline was by far preferable to the other two channels. 2D websites were preferred to VWs. These were the most typical results. All the differences 
were significant with a large effect. From the participants that considered VWs to be better than 2D websites, most valued the ability to negotiate with a real person such as the shop assistant. They found this to be especially beneficial for complex products. When comparing complex products, specifically in terms of which they would feel more confident with, offline was preferred to the other two channels and 2D websites were preferred to VWs. The differences were very large and the average for VWs was negative, meaning on average participants would not use it to purchase such products. This is particularly insightful. The theory this research uses posits that a channel needs a RA to be chosen. If the consumer's perception of a VW for complex products is negative, then the channel is inherently ill-suited for this regardless of the alternative channels.

For simple products, offline and 2D websites were close together and both were preferred to VWs by some margin. For the similar question focusing on confidence, the results were similar with a small but significant preference for offline over both other channels. VWs were not preferred in either comparison, as in complex products, but for simple products however the average was positive. This means on average the consumer would use it, but other channels are preferred. These nuances in the perceived value of a channel are the type of findings this research was designed to identify. If an organization was not pursuing standardization/homogenization strategy and pursuing either a differentiation or harmonization strategy, avoiding or deemphasizing simple products in VWs may help optimize the multichannel retail results.

4.3.5 Findings Related to the Fifth Relative Advantage. The fifth objective stated that VWs may have the RA of more institutional trust compared to 2D websites. In the responses to the question asking whether the payment method was safer offline or in VWs there was no significant difference. The response showed no preference between the two channels; they were almost perfectly matched. When making the comparison with 2D websites, VWs were preferred significantly, with small to medium effect. This is an indication that VWs have the RA of higher institutional trust compared to $2 \mathrm{D}$ websites. There were indications from the qualitative analysis that consumers valued the role of VWs as an institution in relation to trust but it was not expected to be as trustworthy as offline. A feature that was especially appreciated was the buyer not receiving your banking details. Other participants valued the role of the VWs administration in identifying and warning about specific threats. These were indications that a VW as an institution influenced institutional trust positively.

As posited by Choudhury and Karahanna [5] trust can be used to compare retail channels. Therefore, a better understanding of trust improves the ability to make those comparisons. Secondly a better understanding of trust can be used to improve the value a retailer offers to the consumer. This can be achieved by adapting the business model to optimize value [10] or in some other way. Lastly the institution, in this case the VW can take measures to improve the level of institutional trust the consumer perceives [26]. The findings also support the role of institutional trust in relation to the RA of retail channels model: $\mathrm{RA}$ of retail channel $=$
Convenience + Institutional Trust + Efficacy of Information + Enjoyment + RA of unique channel functionalities + RA in specific purchasing stage + RA for specific type of product.

4.3.6 Findings Related to the Sixth Relative Advantage. For some of the questions comparing the channels in relation to enjoyment, there was no significant preference between the three. The average of the results was very high, indicating that participants considered all channels to offer significant enjoyment. For the related questions focusing on the entertainment value, VWs were valued far more than the other two channels. 2D websites were preferred to offline. This was one of the few issues where VWs were preferred to both channels and this indicates that entertainment is a RA of VWs. This is in agreement with other research into VWs that found entertainment to be one of the main strengths [15]. In a second related question about escapism, it was also valued as a RA of VWs over both the other channels. This is also in agreement with other research [17]. While enjoyment was not considered a RA, the support showed this was a strength of VWs.

This is also in agreement with other research that identify enjoyment as a strength of VWs [11]. The findings also support the role of enjoyment, including entertainment, in relation to the RA of retail channels model: RA of retail channel $=$ Convenience + Institutional Trust + Efficacy of Information + Enjoyment + RA of unique channel functionalities + RA in specific purchasing stage + RA for specific type of product.

4.3.7 The Six Relative Advantages of Multichannel Retail Matrix. The findings related to the six RAs are summarized in figure 3. The figure illustrates how the consumer's preference varies across the three channels and six RAs. An organization pursuing a multichannel strategy can adapt their offerings in each channel to fully utilize these different preferences as outlined in this figure. While the initial exploratory qualitative stages showed that VWs were the last preference of the three channels on most issues discussed, framing the comparison with the six RAs shows how they can have a useful and complementary role to play in multichannel retail.

\section{Discussion}

The terms multichannel and omni-channel are widely used for ecommerce by retail practitioners, the financial sector and the business media. While they are often used inconsistently and without an agreed definition they are sometimes presented as a 'silver bullet' that can optimize and futureproof an organization. Knowing the general principle behind multi or omni-channel retail however is of limited benefit. The reality is that understanding the consumer, who is at the same time a technology user [34], is an ongoing challenge that necessitates further exploration.

In parallel, the consumer is exploring the new options constantly being made available to them across all the stages of the purchasing process. The results of this mixed methods research are useful in several ways. 


\begin{tabular}{|c|c|c|c|c|c|c|c|}
\hline & Channel & $\begin{array}{l}\text { RA 1 } \\
\text { Aspects } \\
\text { of } \\
\text { offline }\end{array}$ & $\begin{array}{l}\text { RA 2 } \\
\text { Aspects } \\
\text { of 2D } \\
\text { websites }\end{array}$ & $\begin{array}{l}\text { RA } 3 \\
\text { Vary } \\
\text { usage as } \\
\text { RA of } \\
\text { issues } \\
\text { varies }\end{array}$ & $\begin{array}{l}\text { RA } 4 \\
\text { Usage } \\
\text { different for } \\
\text { simple and } \\
\text { complex } \\
\text { products }\end{array}$ & $\begin{array}{l}\text { RA } 5 \\
\text { Level of } \\
\text { institutional } \\
\text { trust }\end{array}$ & $\begin{array}{l}\text { RA } 6 \\
\text { Level of } \\
\text { enjoyment }\end{array}$ \\
\hline & $\stackrel{\mathscr{\Xi}}{\leftrightarrows}$ & High & Low & Medium & $\begin{array}{l}\text { High } \\
\text { (complex) } \\
\text { High } \\
\text { (simple) }\end{array}$ & High & $\begin{array}{l}\text { High } \\
\text { (Enjoy) } \\
\text { Low } \\
\text { (Entert.) }\end{array}$ \\
\hline \multirow[t]{2}{*}{$\begin{array}{l}\text { Consu } \\
\text {-mer }\end{array}$} & 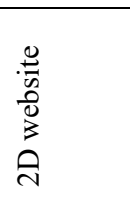 & Low & High & Medium & $\begin{array}{l}\text { Low } \\
\text { (complex) } \\
\text { Medium } \\
\text { (simple) }\end{array}$ & Low & $\begin{array}{l}\text { High } \\
\text { (Enjoy) } \\
\text { Medium } \\
\text { (Entert.) }\end{array}$ \\
\hline & 3 & Medium & Medium & Low & $\begin{array}{l}\text { Medium } \\
\text { (complex) } \\
\text { Medium } \\
\text { (simple) }\end{array}$ & Medium & $\begin{array}{l}\text { High } \\
\text { (Enjoy) } \\
\text { High } \\
\text { (Entert.) }\end{array}$ \\
\hline
\end{tabular}

Figure 3. The six Relative Advantages and three channels

Overall, the combination of several qualitative and quantitative methods gave a deeper understanding of multichannel retail. Applying a methodology similar to comparative case study analysis, the channels were compared between each other on the issues identified in the qualitative analysis that preceded.

For most comparisons, there was a significant difference, that indicated that the sample and the population it represented, had a distinct view about each channel in relation to the question being asked. The most common result for the section comparing three channels, was to consider offline to be preferable to both 2D websites and VWs. 2D was usually preferred to VWs but not always. The differences in preference were usually consistent without great fluctuations. While VWs were usually the least preferable of the pair of channels, the difference was not very big. This is an indication that VWs could in the future compete with the other two established channels. A notable exception was question 35 where VWs were preferred to both offline and 2D websites. This question asked which retail channel was the most entertaining. A second question was 36 that asked which channel made the participant feel they 'got away from it all', resulted in VWs on average having a RA over both other channels in terms of escapism. These results are in line with the findings of the qualitative research that lay the foundations for this work. VWs were also preferred to the other two channels for question 37 that enquired about which channel was more informative about the product. This was not in line with the qualitative analysis where the $2 \mathrm{D}$ websites seemed to be preferred.

For the second section, that compared VWs to the two other channels one at a time, VWs were preferred significantly in most cases. The reason for VWs being more popular in this section to the previous one, was because while the previous section focused on important issues in retail from the consumer's perspective in general, the latter section focused on potential RAs of VWs that arose from the qualitative research. The issue with the most substantial preference was in question 51, the benefit of navigation over online $2 \mathrm{D}, 54$ and 55 , being able to be someone you are not, 58 and 59, instantly delivered virtual products.

\section{Conclusion}

This research explored the RAs of three retail channels. The three channels were evaluated by a survey of 616 participants across 59 issues that had been identified in the qualitative stage of the research. The quantitative analysis revealed the consumer's preferences across these issues.

The first contribution was identifying six RAs summarized in the matrix of three retail channels. The six RAs support a multichannel strategy by enabling a more informed utilization of each channel. Each channel not only has its strengths and weaknesses but also its RA in relation to the other channels. The second contribution was the insight gained on all three channels. The insight gained for VWs was the most significant as they are the newest and least mature. While participants showed a preference for offline and 2D websites in most situations, there was evidence that the emotional reaction, enjoyment, entertainment, sociable shopping, the ability to reinvent yourself, convenience and institutional trust are RAs of VWs in relation to the other two channels. A third contribution was extending Choudhury and Karahanna [5] to include VWs. Originally the model was only used to compare bricks and mortar and 2D websites. A fourth related contribution is the extension of that model by incorporating the RAs identified in order to be effective 
when considering VWs. Enjoyment has been used in many similar models in the past in relation to technology adoption but not for the RA of retail channels. Previous research had identified enjoyment, including entertainment, as a factor in purchasing virtual products [9] and using VWs for business activities [32]. The model proposed is: RA of retail channel $=$ Convenience + Institutional Trust + Efficacy of Information + Enjoyment + RA of unique channel functionalities $+\mathrm{RA}$ in specific purchasing stage + RA for specific type of product.

A fifth and final contribution, was that by allowing the many and varied beliefs of the participants to emerge, the advantage of a value/customer-orientated business model over an activity-role orientated one [24] were supported. The value/customerorientated business model is considered more useful in a multichannel environment. To satisfy the customer, business models should start from the multichannel customer's needs and develop the activities to satisfy those needs rather than implementing typical structures and models regardless of the channel. This is in agreement with Cagnina and Poian [3].

\section{REFERENCES}

[1] Ahn, S.J.G. et al. 2016. Experiencing Nature: Embodying Animals in Immersive Virtual Environments Increases Inclusion of Nature in Self and Involvement With Nature. Journal of Computer-Mediated Communication. 21, 6 (2016), 399-419. DOI:https://doi.org/10.1111/jcc4.12173.

[2] Benford, S. et al. 2001. Collaborative virtual environments. Communications of the ACM. 44, 7 (Jul. 2001), 79-85. DOI:https://doi.org/10.1145/379300.379322.

[3] Cagnina, M.R. and Poian, M. 2009. Beyond e-business models: the road to virtual worlds. Electronic Commerce Research. 9, 1-2 (Jun. 2009), 49-75. DOI:https://doi.org/10.1007/s10660-009-9027-3.

[4] Cheng, X. et al. 2013. Modeling individual trust development in computer mediated collaboration: A comparison of approaches. Computers in Human Behavior. 29, 4 (2013), 1733-1741.

[5] Choudhury, V. and Karahanna, E. 2008. The Relative Advantage of Electronic Channels: A Multidimensional View. Management Information Systems Quarterly. 32, 1 (2008), 179-200.

[6] Chui, M. et al. 2013. Ten IT-enabled business trends for the decade ahead. McKinsey Global Institute White Paper. (2013).

[7] Dholakia, U.M. et al. 2010. Consumer Behavior in a Multichannel, Multimedia Retailing Environment. Journal of Interactive Marketing. 24, 2 (2010), 86-95.

[8] Eisenbeiss, M. et al. 2012. The (Real) World Is Not Enough: Motivational Drivers and User Behavior in Virtual Worlds. Journal of Interactive Marketing. 26, 2 (2012), 4-20.

[9] Gammoh, B.S. et al. 2018. Consumer Attitudes Toward Human-Like Avatars in Advertisements: The Effect of Category Knowledge and Imagery and Imagery. International Journal of Electronic Commerce. 22, 3 (2018), 325348. DOI:https://doi.org/10.1080/10864415.2018.1462939.

[10] Goel, L. and Prokopec, S. 2009. If you build it will they come?-An empirica investigation of consumer perceptions and strategy in virtual worlds. Electronic Commerce Research. 9, 1 (2009), 115-134.

[11] Hamari, J. and Keronen, L. 2017. Why do people buy virtual goods: A metaanalysis. Computers in Human Behavior. 71, (2017), 59-69. DOI:https://doi.org/10.1016/j.chb.2017.01.042.

[12] Harris, P. et al. 2018. Understanding multichannel shopper journey configuration: An application of goal theory. Journal of Retailing and Consumer Services. 44, May (2018), 108-117. DOI:https://doi.org/10.1016/j.jretconser.2018.06.005.

[13] Hassouneh, D. and Brengman, M. 2013. A motivation-based typology of social virtual world users. Computers in Human Behavior. 33, 4 (2013), 330338.
[14] Heitz-Spahn, S. 2013. Cross-channel free-riding consumer behavior in a multichannel environment: An investigation of shopping motives, sociodemographics and product categories. Journal of Retailing and Consumer Services. 20, 6 (2013), 570-578.

[15] Huvila, I. et al. 2010. Social capital in Second Life. Online Information Review. 34, 2 (2010), 295-316.

[16] Kaplan, A.M. and Hanlein, M. 2009. The fairyland of Second Life: Virtua social worlds and how to use them. Business Horizons. 52, 6 (2009), 563 572

[17] Keng, C.J. et al. 2011. Effects of virtual-experience combinations on consumer-related 'sense of virtual community.' Internet Research. 21, 4 (2011), 408-434

[18] Kim, H.W. et al. 2012. What Motivates People to Purchase Digital Items on Virtual Community Websites? The Desire for Online Self-Presentation. Information Systems Research. 23, 4 (2012), 1232-1245.

[19] Konus, U. et al. 2008. Multichannel Shopper Segments and Their Covariates. Journal of Retailing. 84, 4 (2008), 398-413.

[20] Kumar, V. and Venkatesan, R. 2005. Who are the multichannel shoppers and how do they perform?: Correlates of the multichannel shopping behaviour. Journal of Interactive Marketing. 19, 2 (2005), 44-62.

[21] Levy, M. and Weitz, B. 2009. Retailing Management. McGraw Hill.

[22] McKnight, H. et al. 1998. Initial Trust Formation in New Organizational elationships. Academy of Management Review. 23, 3 (1998), 473-490.

[23] McKnight, $\mathrm{H}$. et al. 2002. The impact of initial consumer trust on intention to transact with a web site: a trust building model. Journal of Strategic Information Systems. 11, 3-4 (2002), 297-323.

[24] Osterwalder, A. et al. 2005. Communications of the Association for Information Systems Clarifying Business Models: Origins, Present, and Future of the Concept. Communications of the Association for Information Systems. 16, 16 (2005), 1-25. DOI:https://doi.org/10.1.1.83.7452.

[25] Partala, T. 2011. Psychological needs and virtual worlds: Case Second Life. International Journal of Human Computer Studies. 69, 12 (2011), 787-800.

[26] Pavlou, P. A., Gefen, D. 2004. Building effective online marketplaces with institution-based trust. Information Systems Research. 15, 1 (2004), 667-675. DOI:https://doi.org/10.1287/isre.1040.0015.

[27] Rogers, E.M. 1995. Diffusion of Innovations. Free Press.

[28] Saghiri, S. et al. 2017. Toward a Three-dimensional Framework for Omnichannel. Journal of Business Research. (2017), 53-67. DOI:https://doi.org/10.1016/j.jbusres.2017.03.025.

[29] Schoenbachler, D.D. and Gordon, G.L. 2002. Multi-channel shopping: Understanding what drives channel choice. Journal of Consumer Marketing. 19, 1 (2002), 42-53.

[30] Schroder, H. and Zaharia, S. 2012. Linking multi-channel customer behavior with shopping motives: An empirical investigation of a German retailer. Journal of Retailing and Consumer Services. 15, 6 (2012), 452-468.

[31] Sfenrianto, S. et al. 2018. Assessing the Buyer Trust and Satisfaction Factors in the 2 Research Design. Journal of Theoretical and Applied Electronic Commerce Research. 13, 2 (2018), 43-57. DOI:https://doi.org/10.4067/S0718-18762018000200105.

[32] Shen, J. and Eder, L.B. 2009. Exploring Intentions to Use Virtual Worlds for Business. Journal of Electronic Commerce Research. 10, 2 (2009), 94-103.

[33] Steed, A. et al. 2016. An 'In the Wild' Experiment on Presence an Embodiment using Consumer Virtual Reality Equipment. IEEE Transactions on Visualization and Computer Graphics. (2016).

[34] Venkatesh, V. et al. 2016. Unified Theory of Acceptance and Use of Technology: A Synthesis and the Road Ahead. Journal of the Association for Information Systems. 17, 5 (2016), 328-376.

[35] Wang, L. and Gordon, P. 2011. Trust and institutions: A multilevel analysis. The Journal of Socio-Economics. 40, 5 (2011), 583-593.

[36] Williams, A. 2015. Reality check [Consumer Electronics Virtual Reality 3D] Engineering \& Technology. 10, 2 (2015), 52-55.

[37] Yan, R. et al. 2011. Product distribution and coordination strategies in multi-channel context. Journal of Retailing and Consumer Services. 18, (2011), 19-26.

[38] Zhang, J. et al. 2010. Crafting integrated multichannel retailing strategies. Journal of Interactive Marketing. 24, 2 (2010), 168-180. DOI:https://doi.org/10.1016/j.intmar.2010.02.002.

[39] Zhang, Z. and Gu, C. 2015. Effects of Consumer Social Interaction on Trust in Online Group-Buying Contexts: an Empirical Study in China. Journal of Electronic Commerce Research. 16, 1 (2015), 1-21. 